\title{
Retrograde Melting and Internal Liquid Gettering in Silicon
}

\author{
By Steve Hudelson, Bonna K. Newman, Sarah Bernardis, David P. Fenning, \\ Mariana I. Bertoni, Matthew A. Marcus, Sirine C. Fakra, Barry Lai, \\ and Tonio Buonassisi*
}

Control of metal impurities has proven essential for developing modern semiconductor-based materials and devices. The properties of high-performance integrated circuit, photovoltaic, and thermoelectric devices are tailored by the intentional introduction of dopant species, as well as the removal and passivation of detrimental impurities. ${ }^{[1,2]}$ In addition, the speed and uniformity of several common semiconductor growth methods, including bulk crystal and vapor-liquid-solid (VLS) growth, are regulated by impurity-semiconductor interactions..$^{[3,4]}$

Precise control over impurity chemical states and spatial distributions requires a deep fundamental understanding of the thermodynamics and kinetics regulating impurity phase and transport. Impurity engineering in semiconductors typically involves thermal annealing, as impurity solubility and diffusivity increase exponentially with temperature. However, because of the lack of suitable analytical tools for studying sub-micron-scale distributions of fast-diffusing impurities at elevated temperatures, the vast majority of experimental investigations so far have been conducted at room temperature. As a result, much remains to be explored concerning fundamental impurity-semiconductor reactions at realistic processing temperatures.

It was recently proposed ${ }^{[5]}$ that certain silicon-impurity systems can undergo melting upon cooling, a phenomenon known as retrograde melting. The controlled creation of liquid metalsilicon droplets within or on the surface of a silicon matrix of arbitrary shape could provide novel opportunities to engineer semiconductor-based systems via solid-liquid and vapor-liquid segregation. The phenomenon of retrograde melting, whereby a liquid phase forms from a solid phase upon cooling, has been observed and studied in several organic and inorganic systems, including $\mathrm{Fe}-\mathrm{Zr}^{[6]}$ and Mg-Fe-Si-O. ${ }^{[7]}$ One common pathway

[*] S. Hudelson, ${ }^{[+]}$Dr. B. K. Newman, S. Bernardis, D. P. Fenning, Dr. M. I. Bertoni, Prof. T. Buonassisi

Massachusetts Institute of Technology

Cambridge, Massachusetts, 02139 (USA)

E-mail: buonassisi@mit.edu

Dr. M. A. Marcus, S. C. Fakra

Advanced Light Source

Lawrence Berkeley National Laboratory

Berkeley, California, 94720 (USA)

Dr. B. Lai

Advanced Photon Source

Argonne National Laboratory

Argonne, Illinois, 60439 (USA)

[+] Present address: 1366 Technologies, Lexington, MA 02421, USA for this process to occur is via the catatectic reaction, occurring at an invariant point on a binary phase diagram involving transformation from Solid $\rightarrow$ Solid + Liquid. ${ }^{[8]}$ Many binary systems exhibit such an invariant point, ${ }^{[9]}$ including Ag-In, Cu-Sn, $\mathrm{Fe}-\mathrm{Mn}$, and Fe-S, ${ }^{[10]}$ but very few are semiconducting materials. ${ }^{[11]}$ Retrograde melting in most common silicon-impurity systems cannot occur by this pathway, as these systems do not possess a catatectic point. ${ }^{[11]}$

A second pathway for retrograde melting has been observed in the ternary $\mathrm{Sb}$-Bi-Te system, wherein decreasing solubility of $\mathrm{Te}$ in $\mathrm{Sb}_{2} \mathrm{Te}_{3}$ with decreasing temperature can lead to supersaturation of $\mathrm{Te}$ and formation of liquid droplets at temperatures above the eutectic temperature. ${ }^{[12]}$ We propose that a similar pathway could also produce retrograde melting in binary semiconductor-impurity systems that exhibit retrograde solubility. Due to the high enthalpy of formation of point defects in certain semiconductors, the solid solubility of an impurity within the crystal structure increases with temperature, reaching a maximum well above the eutectic temperature. Many dissolved elements in silicon demonstrate this property, ${ }^{[13]}$ including many of the $3 \mathrm{~d}$ transition metals such as iron, copper, and nickel. ${ }^{[14]}$ It is hypothesized that retrograde solubility can lead to retrograde melting, ${ }^{[5]}$ if supersaturation occurs at a temperature above the eutectic temperature (as demonstrated in Figure 1a).

To study temperature-dependent silicon-impurity reactions at the micro-scale, we carried out synchrotron-based hard X-ray microprobe experiments at high temperatures (up to $1500^{\circ} \mathrm{C}$ ). We adapted an in situ microscope hot stage (Linkam TS1500) at beamlines 10.3.2 at the Advanced Light Source ${ }^{[15]}$ and 2-ID-D at the Advanced Photon Source. ${ }^{[16]}$ X-ray fluorescence microscopy ( $\mu$-XRF) mapping was used to investigate the spatial distribution of transition metal-rich particles as small as $50 \mathrm{~nm}^{[17,18]}$ in silicon matrices. The chemical state of precipitated impurities detected by $\mu$-XRF was determined by X-ray absorption microspectroscopy ( $\mu$-XAS). ${ }^{[18]}$

To verify that $\mu$-XAS can distinguish between liquid and solid phases in metal-Si systems, we prepared a standard sample (see Experimental, sample 1) consisting of a thin layer $(\sim 1 \mu \mathrm{m})$ of e-beam evaporated $\mathrm{Cu}, \mathrm{Ni}$, and $\mathrm{Fe}$ sandwiched between a mc-Si wafer and a thin piece $(<15 \mu \mathrm{m})$ of monocrystalline Czochralski Si (CZ-Si). The sample was then heated to $1045^{\circ} \mathrm{C}$, well above the $\mathrm{Cu}-\mathrm{Si}$ and Ni-Si eutectic temperatures, to ensure a liquid metal-silicon mixture. $\mu$-XRF mapping of the standard at $1045^{\circ} \mathrm{C}$ revealed that the previously continuous film had dewetted, suggesting the presence of a high-temperature liquid state. After cooling the sample to room temperature, a visual inspection revealed that the Si cap layer was fused to the 


\section{(a)}
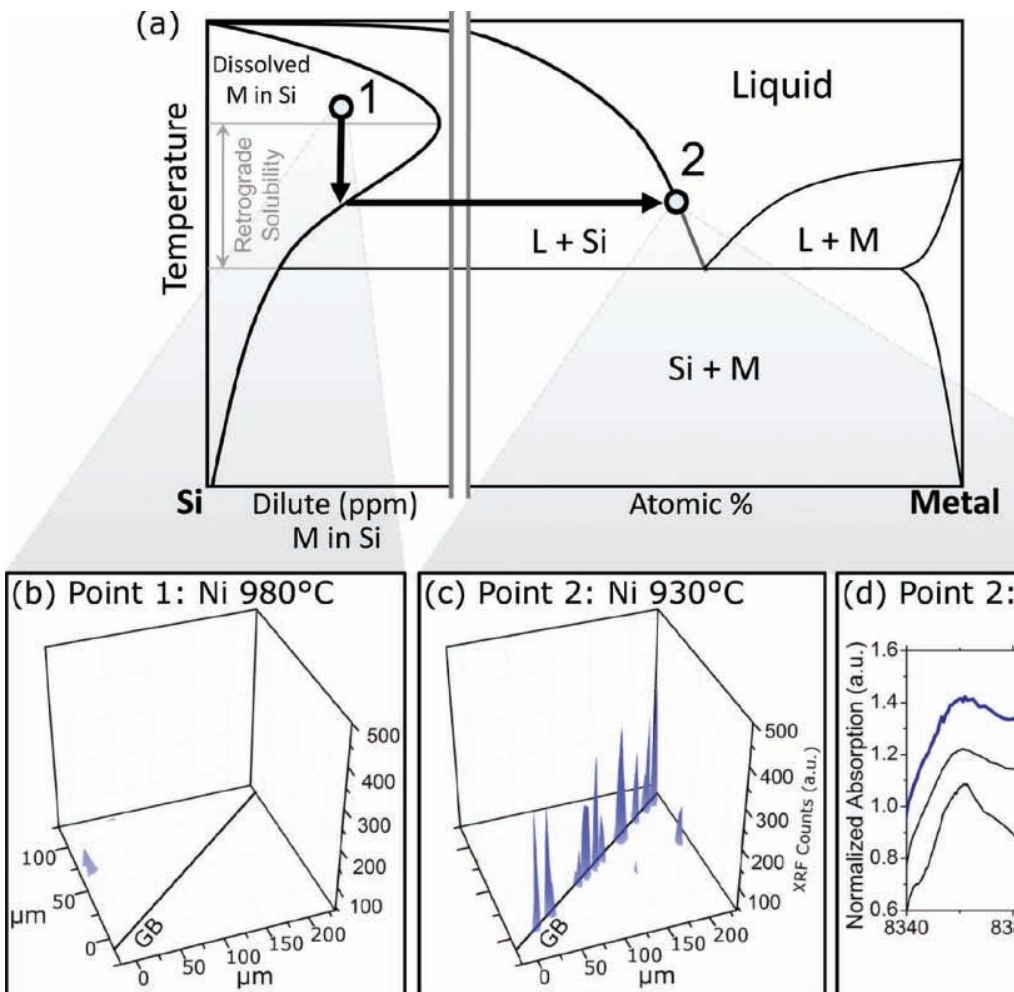

(c) Point 2: Ni $930^{\circ} \mathrm{C}$
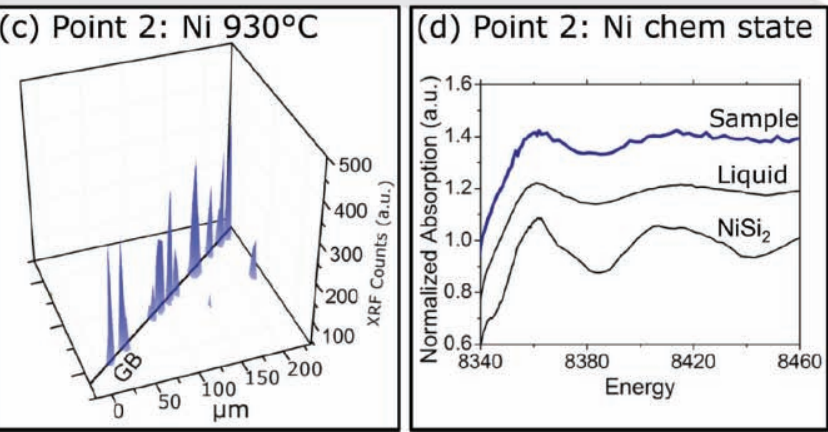

Figure 1. Formation of liquid droplets via retrograde melting in silicon. (a) A schematic binary phase diagram demonstrates how retrograde solubility of a dissolved metal (M) in silicon (point 1) can lead to retrograde melting upon supersaturation above the eutectic temperature, forming liquid $\mathrm{M}$-Si droplets (point 2). $\mu$-XRF maps of a grain boundary region of a crystalline silicon sample above (b) and below (c) the solidus curve show precipitation of metal-rich particles upon cooling. (d) The particles are identified as liquid droplets by Ni K-edge $\mu$-XAS analysis. Solid metal-silicide phases below the binary eutectic are omitted for clarity.

mc-Si substrate, further indicating a high-temperature transition through a liquid state. The Ni K-edge $\mu$-XAS spectrum of the standard at $1045^{\circ} \mathrm{C}$ confirmed a liquid $\mathrm{Ni}$-Si phase distinct from solid room-temperature $\mathrm{NiSi}_{2}$ (Figure 1d), demonstrating that these phases can be distinguished via XAS. Similar spectra of solid and liquid phases were obtained on samples with evaporated single metals only.

To test the hypothesis of retrograde melting in silicon, a high-purity multicrystalline silicon (mc-Si) wafer with a layer of electron-beam evaporated $\mathrm{Cu}, \mathrm{Ni}$ and Fe was annealed at $1140^{\circ} \mathrm{C}$ for thirty minutes to intentionally contaminate the sample (see Experimental, sample 2). The sample was then quenched to trap the metal in the dissolved, supersaturated state. Contamination levels were estimated based on the solubility limit ${ }^{[14,19]}$ of the metals at $1140^{\circ} \mathrm{C}: 1 \times 10^{18} \mathrm{~cm}^{-3}$ $\mathrm{Ni}, 3 \times 10^{18} \mathrm{~cm}^{-3} \mathrm{Cu}$, and $6 \times 10^{15} \mathrm{~cm}^{-3} \mathrm{Fe}$; the presence of multiple impurities is expected to change these solubility limits slightly. ${ }^{[3]}$ The target $\mathrm{Ni}$ and $\mathrm{Cu}$ concentrations are above equilibrium solubility at the metal-silicon eutectic temperature, satisfying the proposed condition for retrograde melting and metal-Si liquid droplet formation illustrated in Figure $1 \mathrm{a}$.

The sample was rapidly heated $\left(100^{\circ} \mathrm{C} \mathrm{min}^{-1}\right)$ above the eutectic temperature in the in situ microscope stage. A $\mu-X R F$ map of a grain boundary (GB) region displayed in Figure $1 \mathrm{~b}$, at $980^{\circ} \mathrm{C}$, reveals that no metal precipitates were present above the detection limits (approximately $10^{14}-10^{15} \mathrm{~cm}^{-2}$, Refs. ${ }^{[17,18]}$ ).
The sample was then cooled to $930^{\circ} \mathrm{C}$ and remapped, showing the formation along the $\mathrm{GB}$ of particles containing $\mathrm{Cu}, \mathrm{Ni}$, and Fe (Figure 1c.), the Ni $\mu$-XAS spectra of which are consistent with the liquid Ni-Si phase in our standard sample (Figure 1d). The initial nucleation of the liquid droplets occurred at a point below the expected solubility limit (solidus), likely because there was some out-diffusion of metals during quenching/cooldown and reheating (lowering total concentration of dissolved metals), and possibly due to a high nucleation energy barrier for metalsilicon precipitates. ${ }^{[20,23]}$

The formation of liquid droplets in mc-Si can be explained with the schematic phase diagram of Figure 1a. The sample initially has a high concentration of dissolved metals within the silicon, and is rapidly heated to a temperature above the eutectic temperature, in the region of retrograde solubility. As the sample is cooled, the solidus is crossed, and liquid droplets form due to precipitation of the dissolved impurities. Thus a localized melting reaction occurs while cooling, i. e., retrograde melting is observed.

Existence of metal-silicon liquid droplets should result in the segregation gettering of other dissolved metal species. To test this hypothesis, a sample containing liquid metal-silicon droplets formed by retrograde melting was held at high temperature $\left(930^{\circ} \mathrm{C}\right)$ while taking successive $\mu$-XRF maps of the same $\mathrm{GB}$, as shown in Figures 2a-c. Initially, we observed large liquid precipitates containing copper and nickel, consistent with their high diffusivity and solubility in silicon. ${ }^{[14]}$ The XRF signal from a 

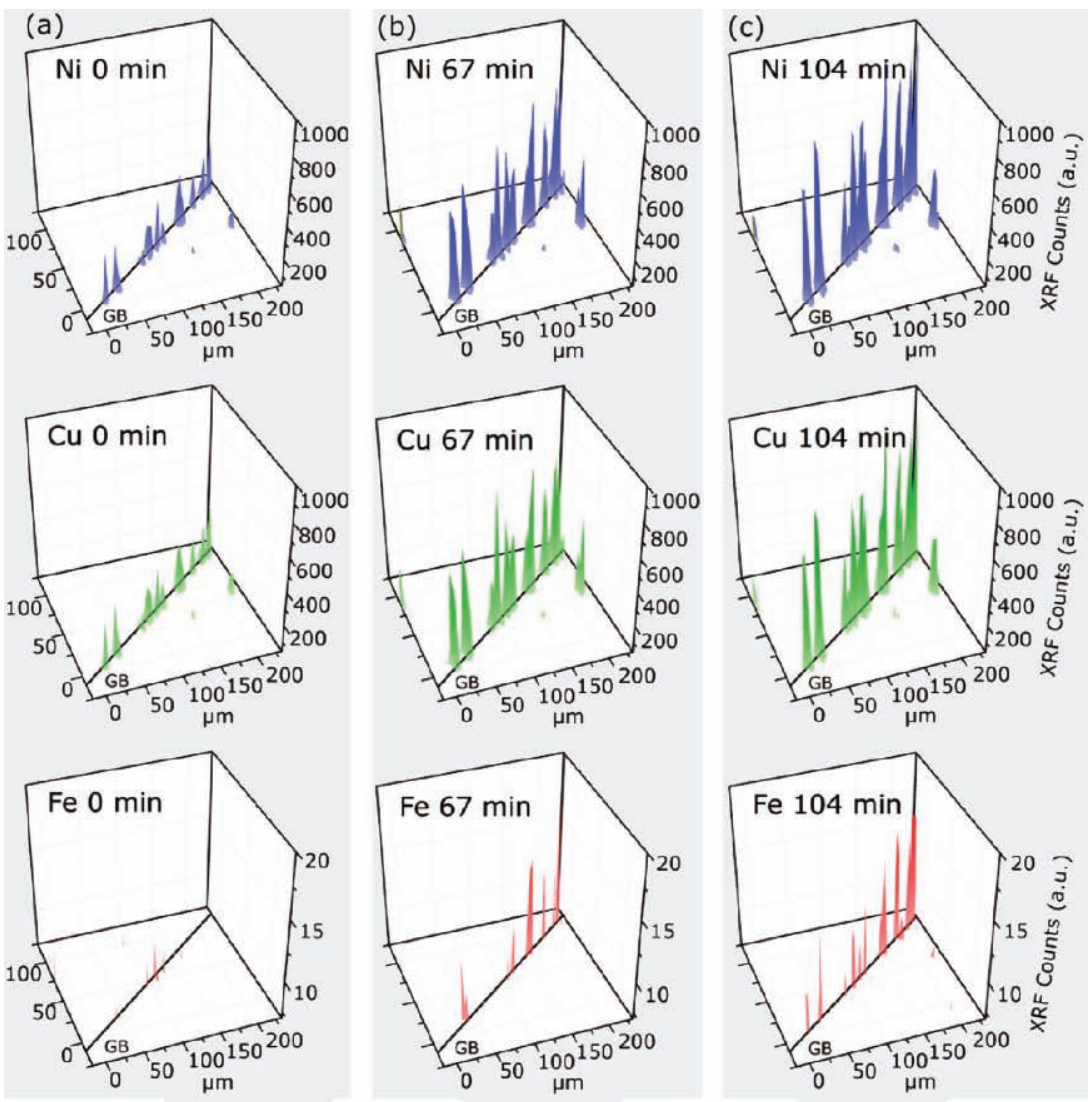

(d)

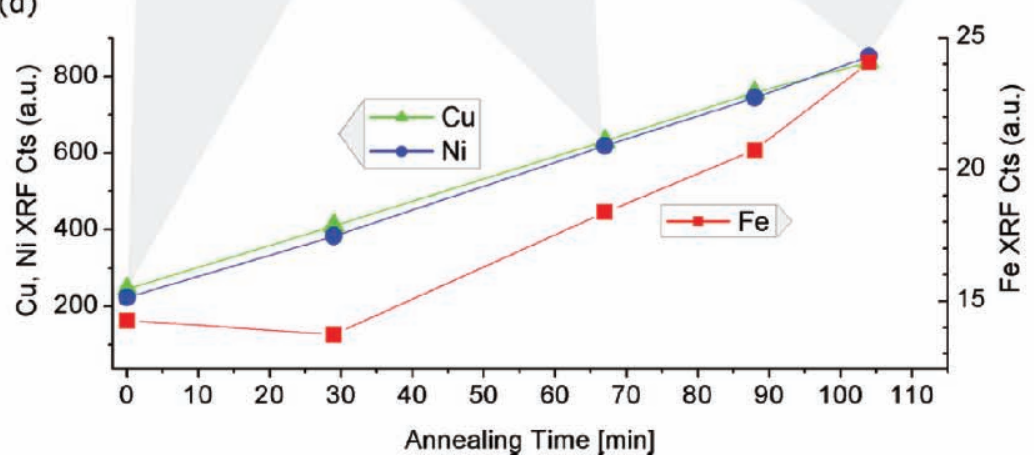

Figure 2. High-temperature gettering of metals to liquid droplets along a grain boundary. (a-c) $\mu$-XRF maps, shown in $3 \mathrm{D}$, taken at $930^{\circ} \mathrm{C}$. Elemental distribution maps show the initial clustering of $\mathrm{Cu}$ precipitates along the grain boundary, with very small amounts of Fe. After $67 \mathrm{~min}$ utes, both $\mathrm{Cu}$ and Fe precipitates have grown. After 104 minutes, $\mathrm{Cu}$ and Fe particles continue to grow. (d) Concentration plots (normalized with respect to concentration at $\mathrm{t}=104 \mathrm{~min}$ ) of $\mathrm{Cu}, \mathrm{Ni}$, and $\mathrm{Fe}$ in a representative particle as a function of time show that Fe is effectively gettered to liquid droplets. $\mu$-XAS measurements of $\mathrm{Ni}$ in the particles (not shown) confirm the liquid state of these droplets.

representative particle was spatially integrated to determine the total amount of precipitated metal as a function of time. The $\mu$ XRF counts of $\mathrm{Cu}$ and $\mathrm{Ni}$ were found to increase approximately linearly (Figure 2d), consistent with a diffusion-limited growth process. After 30 minutes, the Fe concentration in these liquid $\mathrm{Cu}-\mathrm{Ni}-\mathrm{Si}$ droplets surpassed the noise level and also increased linearly. The iron accumulation in the liquid copper and nickel alloy droplets was consistent with a segregation gettering effect, illustrating internal gettering to a liquid droplet.
To correlate the observation of liquid metal alloy droplets with previous reports of mixed-metal silicides in mc-Si systems, a final experiment was performed. A sample was intentionally contaminated with $\mathrm{Cu}$, $\mathrm{Fe}$ and $\mathrm{Ni}$ at $1140^{\circ} \mathrm{C}$ and then annealed insitu at $1080^{\circ} \mathrm{C}$ for approximately 12 hours to allow formation, growth, and stabilization of liquid droplets (see Experimental, sample 3). The sample was then slowly cooled $\left(1-3{ }^{\circ} \mathrm{C}\right.$ $\min ^{-1}$ ) while characterized by $\mu$-XRF/XAS as illustrated in Figure 3. We acquired $\mu$-XRF every 25 minutes (acquisition time of $100 \mathrm{~ms}$ per point) maps on a large liquid droplet observed within a $100 \times 100 \mu \mathrm{m}^{2}$ area, probing the spatial distribution of metals while cooling. $\mu$-XAS measurements (acquisition times of 2-5 seconds per energy point), which were obtained after each map, provided information about the chemical states of precipitated metals. At high temperature, metals were observed homogeneously distributed within the liquid droplets. As the sample was cooled, the liquid alloy began to decompose and Ni-rich regions formed at the edges of the particle, while the large central region remained a mixed-metal liquid. Further cooling caused the Ni-rich regions to grow larger. Between $755^{\circ} \mathrm{C}$ and $700^{\circ} \mathrm{C}$, $\mathrm{Cu}$ was also observed to segregate from the core of the precipitate. Between $745^{\circ} \mathrm{C}$ and $685^{\circ} \mathrm{C}$, the chemical state of the core precipitate changed from liquid to solid, as evidenced by $\mu$-XAS data displayed in Figure $3 b$. The eutectic temperatures of a multinary metal-silicon system can be lower than the eutectic temperature of pure binary metal-Si systems. ${ }^{[21]}$

Based on our experimental observations, we propose a schematic phase diagram (Figure 3c) of the evolution of a liquid droplet during cooling from high temperatures involving decomposition of the high temperature liquid into different phases, followed by solidification to solid metal silicide cores. In the example shown in Figure 3a and Figure $3 \mathrm{~b}$, the composition of the particles is initially nickel-rich with respect to the eutectic composition. The particle begins as a homogeneous metal-silicon liquid droplet at high temperature, and is in the liquid region of the pseudo-binary phase diagram for the $\mathrm{Cu}_{3} \mathrm{Si}_{-} \mathrm{NiSi}_{2}$ system (the Si-rich corner of the $\mathrm{Cu}-\mathrm{Ni}-\mathrm{Si}$ phase diagram ${ }^{[22]}$ ). In the liquid state, the particle acts as an efficient site for the aggregation of metal atoms dissolved in the bulk by segregation gettering to the liquid droplets. Such a homogeneous phase has been predicted as a precursor to the formation of the mixed-metal silicides found in as-grown solar cell material. ${ }^{[5]}$ During cooling, relaxation gettering can also occur as 
the remaining dissolved species become supersaturated, and preferentially diffuse to existing defects to minimize interfacial and volume-change strain energy. ${ }^{[23]}$

As the temperature drops to the liquidus, $\mathrm{NiSi}_{2}$ begins to precipitate, migrating away from the homogeneous liquid droplets and forming nodules or separate precipitates. Due to the high diffusivity of nickel and copper at elevated temperatures, ${ }^{[14]}$ significant rearrangement of the particles is possible, as evidenced by the changing ratios of $\mathrm{Cu}$ and $\mathrm{Ni}$ in the bicolor coded $\mu$-XRF maps in Figure 3a. The composition follows the liquidus towards the eutectic composition and Ni continues to precipitate to solid $\mathrm{NiSi}_{2}$, while $\mathrm{Cu}$ stays in solution, shifting the concentration of $\mathrm{Cu}$ in the liquid towards the eutectic composition. When the eutectic point is reached on the phase diagram, further cooling causes the droplet to decompose into two solid mixed-metal silicide phases: a $\eta$ - $\mathrm{Cu}_{3}$ Si-like phase and a $\mathrm{NiSi}_{2}$-like phase. Both phases are known to accommodate up to atomic percents of substitutional metal species, as reported in alloy experiments. ${ }^{[21]}$ The phases observed, as well as their morphology, agree well with previous investigations of solid-phase mixed-metal silicides in silicon. ${ }^{[5,24]}$

In summary, our experimental observations demonstrate a novel impurity precipitation pathway in silicon, illustrated in Figure 4. Through temperature-dependent X-ray microprobe measurements, we have observed the formation of liquid metal-silicon droplets upon cooling of solid silicon, a phenomenon known as retrograde melting. We have demonstrated that these liquid droplets getter other dissolved impurities, consistent with solid-to-liquid segregation. Slowly cooling these liquid metal-silicon alloy droplets to room temperature resulted in the decomposition of the homogeneous liquid alloy into two solid multiple-metal silicide phases. To explain these phenomena, we have used appropriate equilibrium phase diagrams (Figure 1a and Figure 3c). The precipitation pathway proposed herein may help explain previous reports ${ }^{[24-29]}$ of mixed-metal silicide precipitates in silicon that can exhibit the same nanoscale spatial segregation into $\mathrm{Cu}$-rich and Ni-rich silicide phases evident in Figure 3. It is proposed that these precipitates observed in as-grown mc-Si may form via decomposition of homogeneous liquid metal-silicon alloy droplets either incorporated during crystallization or precipitated during cooldown.

Our observation of novel impurity reactions in silicon, the most common semiconductor material, has broad implications. By developing crystal growth processes that take advantage of these phenomena, the distribution of deleterious impurities, such as iron, may be better controlled, improving electrical performance and widening the range of acceptable feedstock qualities for low-cost photovoltaic applications. Precipitation of metals via retrograde melting may also be applied to control

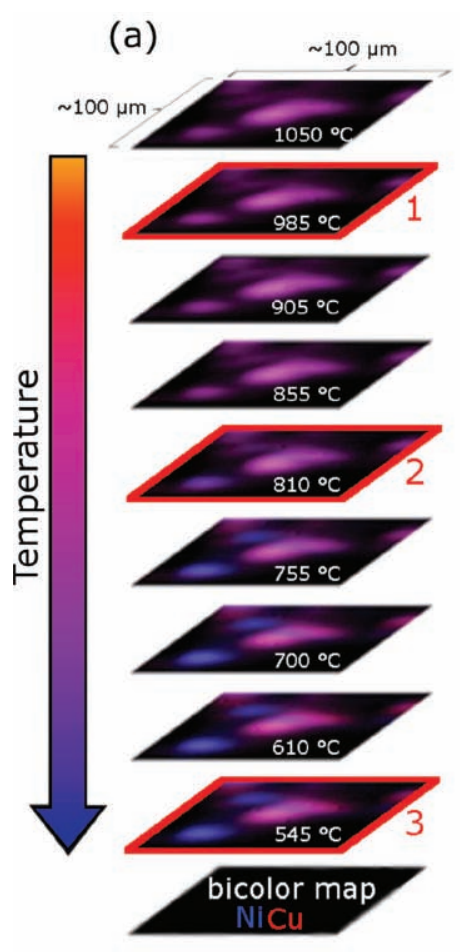

(b)

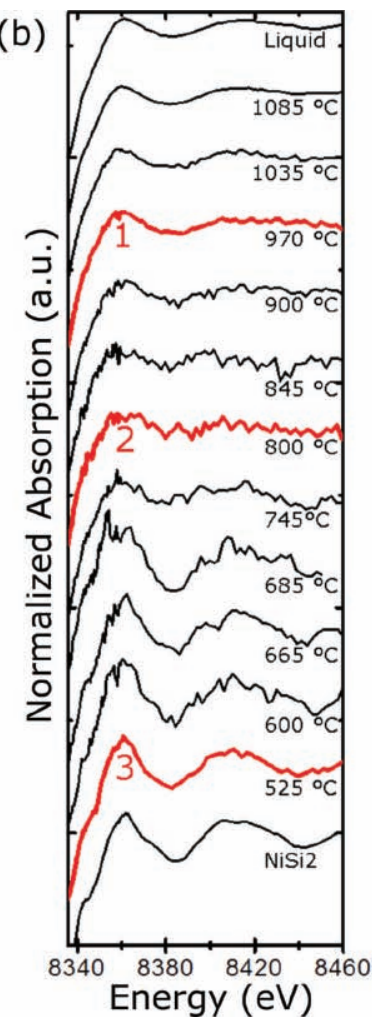

(c)
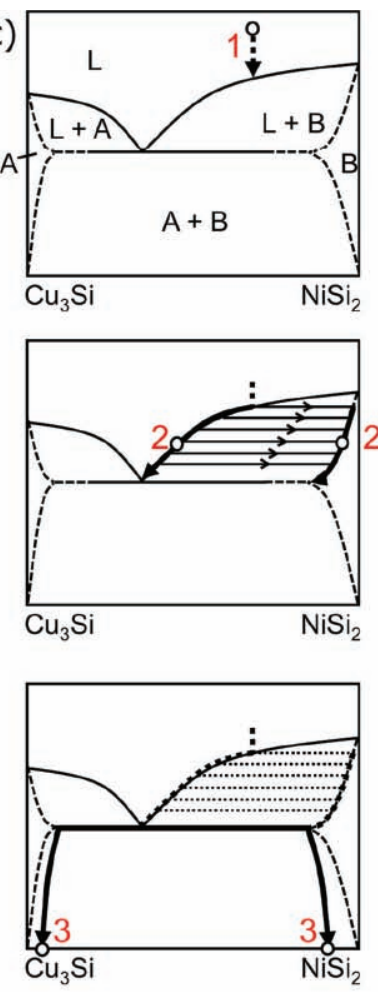

Figure 3. Phase segregation during cooling. (a) Successive $\mu-X R F$ maps of a cluster of particles show its evolution from homogeneous liquid droplets (higher T) to segregated solid precipitates (lower T). The bicolor coded maps show colocation of Ni (blue) and Cu (red) at higher T and precipitation at lower T. (b) Successive Ni K-edge $\mu$-XAS measurements of the main particle. Liquid metal-silicon alloy (top) and solid $\mathrm{NiSi}_{2}$ (bottom) standard spectra are shown for comparison. (c) The evolution of the particle from liquid droplets to solid silicide precipitates is explained by means of a pseudobinary phase diagram. The final phases (denoted by state 3 ) are non-equilibrium phases, as the samples were not cooled sufficiently slowly to allow equilibration. 


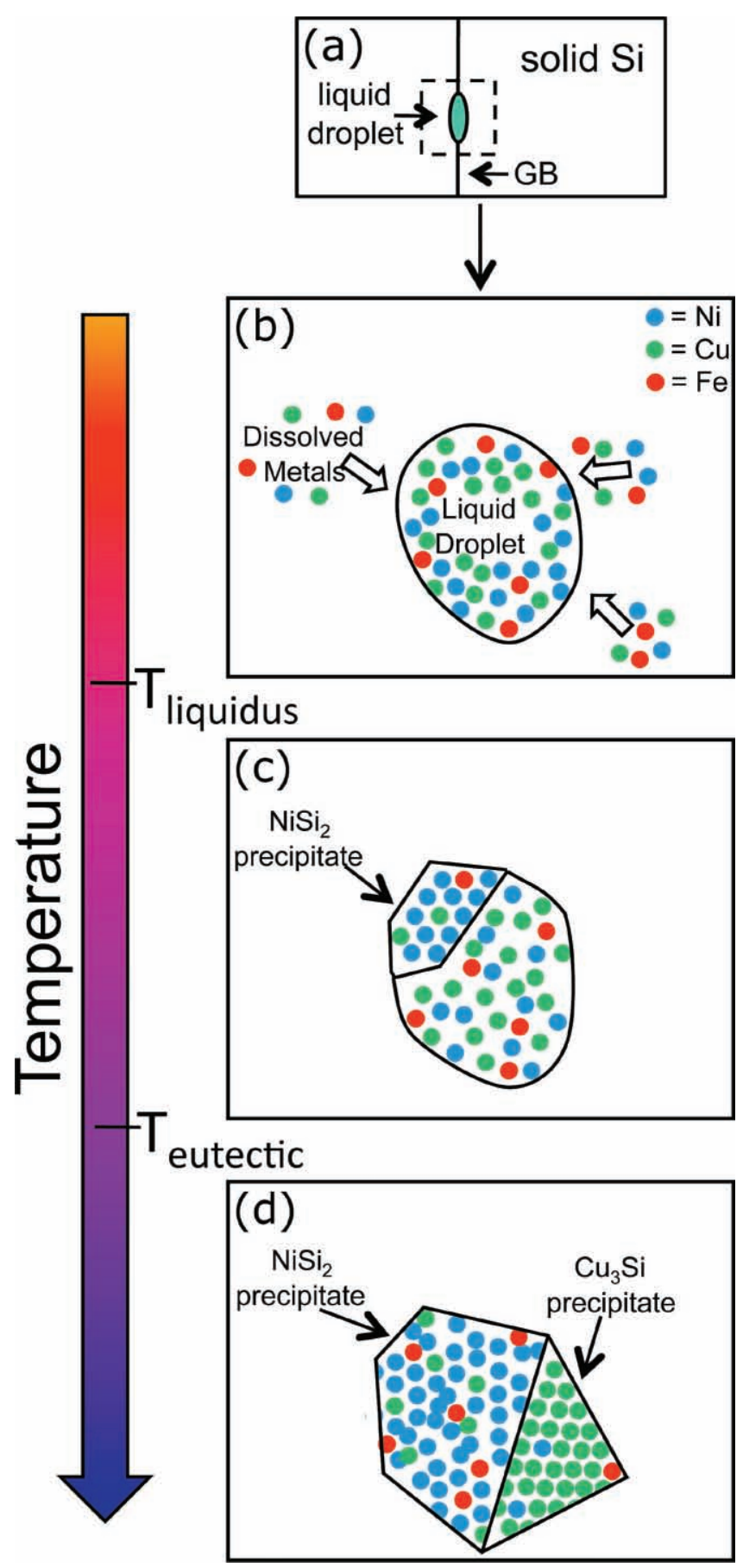

Figure 4. Schematic description of droplet formation, gettering, and precipitation. Two possible formation mechanisms of liquid droplets during crystal growth: (a) direct incorporation from the melt along grain boundaries, and (b) from supersaturated metals precipitating at favorable nucleation sites along grain boundaries. (c) At high temperature, liquid droplets grow by segregation of metals from the bulk. (d) Upon cooling, as the temperature drops below the liquidus temperature (determined by the starting composition), $\mathrm{Ni}$ begins to precipitate into $\mathrm{NiSi}_{2}$. The composition of the remaining liquid moves towards the eutectic composition. (e) At the eutectic temperature, the eutectic composition becomes unstable, and decomposes into two phases: $\mathrm{Cu}_{3} \mathrm{Si}$ nodules surrounding a mixed-metal silicide core. the distributions of metals in functional substrates or devices, enabling the creation of self-assembled metal alloy contacts on 3-dimensional silicon surfaces with large aspect ratios. Finally, we suspect these processes to have a wider applicability beyond the $3 \mathrm{~d}$ transition metals in silicon. Analysis of impurity solubility data ${ }^{[13]}$ and phase diagrams ${ }^{[11]}$ for various systems (as demonstrated in Figure 1), reveals that similar phenomena may occur in other systems, such as germanium and silicon doped with high concentrations of noble metals. These metal impurity-semiconductor reactions may lead to new opportunities to engineer high-performance materials and devices on the nanometer scale.

\section{Experimental Section}

Three $5 \times 5 \mathrm{~mm}^{2}$ samples were laser-cut from $200-\mu \mathrm{m}$ thick ingot multicrystalline silicon wafers grown by directional solidification and obtained from industrial solar cell manufacturers. All samples were cleaned with acetone and ethanol, then lightly etched in a solution of hydrofluoric, nitric, and acetic acids. The three samples were prepared as follows:

Sample 1: Alternating layers of metal $\left(320 \mathrm{~nm} \mathrm{Ni}{ }_{0.8} \mathrm{Fe}_{0.2}, 300 \mathrm{~nm} \mathrm{Cu}\right.$, $300 \mathrm{~nm} \mathrm{Ni}{ }_{0.8} \mathrm{Fe}_{0.2}, 300 \mathrm{~nm} \mathrm{Cu}$ ) were e-beam evaporation deposited. The metal-covered side was capped with a $<15 \mu \mathrm{m}$ piece of monocrystalline Czochralski Si and heated in-situ to measure the chemical state of liquid metal-silicon alloys.

Sample 2: Alternating layers of metal $\left(320 \mathrm{~nm} \mathrm{Ni} \mathrm{F}_{0.8} \mathrm{Fe}_{0.2}, 300 \mathrm{~nm} \mathrm{Cu}\right.$, $300 \mathrm{~nm} \mathrm{Ni} 0.8 \mathrm{Fe}_{0.2}, 300 \mathrm{~nm} \mathrm{Cu}$ ) were e-beam deposited. The metal-coated side was covered with another mc-Si wafer and annealed at $1140{ }^{\circ} \mathrm{C}$ for $\sim 30$ minutes, cooled at a rate of $\sim 5-30{ }^{\circ} \mathrm{C} \mathrm{s}^{-1}$, and quenched to room temperature (oil quench, $\sim 100-200{ }^{\circ} \mathrm{C} \mathrm{s}^{-1}$ ). After an acetone rinse and light hand polishing, an etch of nitric, acetic, and hydrofluoric acids (11:2:4 ratio) removed any metals that had diffused to the outer surfaces. This slightly anisotropic etch revealed grain boundaries; highenergy grain boundaries (typically exhibiting high curvature and faceting) were selected for observation of metal heterogeneous nucleation.

Sample 3: Alternating layers of metals ( $3 \mathrm{~nm} \mathrm{Fe}, 15 \mathrm{~nm} \mathrm{Ni}, 35 \mathrm{~nm} \mathrm{Cu}$ ) were sputtered. The sample was annealed at $1140{ }^{\circ} \mathrm{C}$ for 30 minutes, then quenched to room temperature. The sample was cleaned in acetone and isopropanol to remove organic contamination, then handpolished and chemical etched (see above), leaving only metals dissolved or precipitated in the bulk.

Given the abundance of metals on the surface during annealing, the bulk concentration of metals in all samples was determined solely by the solid solubility of each metal at the annealing temperature.

Synchrotron-based X-ray fluorescence microprobe measurements were performed at the Advanced Light Source Beamline 10.3.2, ${ }^{[15]}$ with beam spot size as small as $5 \times 5 \mu \mathrm{m}^{2}(\mathrm{H} \times \mathrm{V})$; and the Advanced Photon Source Beamline 2-ID-D, ${ }^{[16]}$ with a beam spot of diameter $0.2 \mu \mathrm{m}$. $\mu$-XRF elemental distribution maps were obtained using an incident photon beam of $10 \mathrm{keV}$, and $x-y$ scanning a sample oriented at 35 degrees relative to the incoming beam while detecting resulting fluorescence emission. In order to determine the relative concentrations of elements, the XRF signal was spatially integrated to quantify the total counts of a given element. The particle described in Figure $2 \mathrm{~g}$ was integrated with a $27 \times 27 \mu \mathrm{m}^{2}$ box to encompass the entire particle during ripening.

X-ray absorption microspectroscopy ( $\mu$-XAS) was performed in fluorescence mode at the Advanced Light Source Beamline 10.3.2. Liquid-phase alloys were identified by their XAS signal: the reduction in amplitude of the EXAFS oscillations across the transition from a solid to a liquid is consistent with the reduction in order of a liquid relative to a solid. Solid phases were identified by comparing the XAS spectra of samples with reference spectra.

For high-temperature $\mu$-XRF and $\mu$-XAS measurements, we employed a Linkam TS1500 microscope stage capable of heating an $8 \mathrm{~mm}$ diameter sample to $1500^{\circ} \mathrm{C}$. With the stage in vertical orientation, a tungsten 
wire bent into a ring held the sample in contact with the heating cup. The temperature of a given sample can be determined with $\pm 8 \%$ absolute uncertainty while temperature differentials for a single sample can be measured within $2 \%$ relative uncertainty, as derived from temperature calibrations with X-ray diffraction, thermocouple, and optical pyrometry techniques. The stage has gas inlets and outlets to provide a highpurity nitrogen atmosphere while samples are heated. The high-purity nitrogen displaces oxygen, thus limiting surface oxidation and slowing the out-diffusion of dissolved metals within the silicon samples. Additional protection against oxidation was provided by an oxygen getter consisting of a $\sim 10 \mathrm{mg}$ titanium piece held in close proximity to the sample. As neither titanium nor tungsten were transition metals of interest in this study, possible contamination from the getter and sample holder was not a concern. To contain ambient atmosphere, we used a $10-\mu \mathrm{m}$-thick single-crystal Si window that has $90 \%$ transmission of incident $10 \mathrm{keV}$ $\mathrm{x}$-rays, and transmission of exiting $\mathrm{Fe}, \mathrm{Ni}$, and $\mathrm{Cu} \mathrm{K}$-line $\mathrm{x}$-rays of $68 \%$, $78 \%$, and $82 \%$, respectively, and is free of transition-metal impurities.

\section{Supporting Information}

Supporting Information is available from the Wiley Online Library or from the author.

\section{Acknowledgements}

We thank J. McGinn and S. Cortes at McCrone Scientific for their outstanding equipment support; M. Heuer, S. Langkau, M.D. Pickett, S. Riepe, and E.L. Thomas for enlightening discussions; S. Speakman for assistance with XRD; and Y.S. Lee for assisting with e-beam evaporation and sputtering. Support for this research was provided by the U.S. Department of Energy, under contract number DE-FG36-09GO19001, and through the generous support of Doug Spreng and the Chesonis Family Foundation. S. Hudelson and D.P. Fenning acknowledge the National Science Foundation; B. Newman the Claire Boothe Luce Foundation. The Advanced Light Source and the Advanced Photon Source are supported by the Director, Office of Science, Office of Basic Energy Sciences, of the U.S. Department of Energy under Contracts No. DE-AC02-05CH11231 and DE-AC02-06CH11357, respectively. This work was performed in part at the Center for Nanoscale Systems (CNS), a member of the National Nanotechnology Infrastructure Network (NNIN), which is supported by the National Science Foundation under NSF award no. ECS-0335765. CNS is part of the Faculty of Arts and Sciences at Harvard University.

Received: December 18, 2009

Published online: July 29, 2010

[1] H. J. Queisser, E. E. Haller, Science 1998, 281, 945.

[2] D. G. Cahill, W. K. Ford, K. E. Goodson, G. D. Mahan, A. Majumdar, H. J. Maris, R. Merlin, S. R. Phillpot, J. Appl. Phys. 2003, 93, 793.
[3] K. Tang, G. M. Tranell, E. J. Øvrelid, M. Tangstad, in Crystal Growth of Silicon for Solar Cells (Eds: K. Nakajima, N. Usami), Springer, Berlin 2010.

[4] E. I. Givargizov, J. Cryst. Growth 1975, 31, 20.

[5] T. Buonassisi, M. Heuer, A. A. Istratov, M. D. Pickett, M. A. Marcus, B. Lai, Z. Cai, S. M. Heald, E. R. Weber, Acta Mater. 2007, 55, 6119.

[6] F. Stein, G. Sauthoff, M. Palm, J. Phase Equilib. 2002, 23, 480.

[7] D. H. Speidel, R. H. Nafziger, Science 1966, 152, 1367.

[8] S. Wagner, D. A. Rigney, Metall. Trans. 1974, 5, 2155.

[9] R. Ferro, A. Saccone, S. Delfino, A. M. Cardinale, D. Maccio, Metall. Trans. B 1996, 27, 979.

[10] M. Stier, M. Rettenmayr, J. Cryst. Growth 2008, 311, 137.

[11] H. Okamoto, Desk Handbook: Phase Diagrams for Binary Alloys, ASM International, Materials Park, $\mathrm{OH} 2000$.

[12] N. K. Abrikosov, L. V. Poretskaya, Izv. Akad. Nauk Neorg. Mater. 1965, 1, 503.

[13] F. A. Trumbore, Bell Syst. Tech. J. 1960, 39, 205.

[14] E. R. Weber, Appl. Phys. A-Mater. 1983, 30, 1.

[15] M. A. Marcus, A. A. MacDowell, R. Celestre, E. Domning, K. Franck, A. Manceau, G. Morrison, T. Miller, H. A. Padmore, R. E. Sublett, J. Synch. Rad. 2004, 11, 239.

[16] Z. Cai, B. Lai, W. Yun, I. McNulty, A. Khounsary, J. Maser, P. Ilinski, D. Legnini, E. Trakhtenberg, S. Xu, B. Tieman, G. Wiemerslage, E. Gluskin, AIP Conf. Proc. 2000, 521, 31.

[17] S. A. McHugo, A. C. Thompson, C. Flink, E. R. Weber, G. Lamble, B. Gunion, A. MacDowell, R. Celestre, H. A. Padmore, Z. Hussain, J. Cryst. Growth 2000, 210, 395.

[18] T. Buonassisi, A. A. Istratov, M. A. Marcus, M. Heuer, M. D. Pickett, B. Lai, Z. Cai, S. M. Heald, E. R. Weber, Solid State Phenom. 2005, 108-109, 577.

[19] K. Graff, Metal impurities in silicon-device fabrication, Springer, Berlin 2000.

[20] E. Nes, J. Washburn, J. Appl. Phys 1973, 44, 3682.

[21] S. Langkau, M. Heuer, H. J. Höbler, K. Bente, G. Kloess, J. Alloy Compd. 2008, 474, 334.

[22] Y. A. Chang, J. P. Neumann, A. Mikula, D. Goldberg, Phase Diagrams Thermodynamic Properties Ternary Copper-Metal Systems, Vol. 6, INCRA, New York 1979, 597.

[23] S. M. Myers, M. Seibt, W. Schroter, J. Appl. Phys. 2000, 88, 3795.

[24] M. Heuer, T. Buonassisi, A. A. Istratov, M. D. Pickett, M. A. Marcus, A. M. Minor, E. R. Weber, J. Appl. Phys 2007, 101, 123510.

[25] H. Nordmark, M. Di Sabatino, E. J. Øvrelid, J. C. Walmsley, R. Holmestad, Proc. 22nd European Photovoltaics Solar Energy Conf. 2007, 1710.

[26] T. Buonassisi, A. A. Istratov, M. D. Pickett, M. Heuer, J. P. Kalejs, G. Hahn, M. A. Marcus, B. Lai, Z. Cai, S. M. Heald, T. F. Ciszek, R. F. Clark, D. W. Cunningham, A. M. Gabor, R. Jonczyk, S. Narayanan, E. Sauar, E. R. Weber, Prog. Photovoltaics 2006, 14, 513.

[27] M. Heuer, T. Buonassisi, M. A. Marcus, A. A. Istratov, M. D. Pickett, T. Shibata, E. R. Weber, Phys. Rev. B 2006, 73, 235204.

[28] A. G. Cullis, L. E. Katz, Philos. Mag. 1974, 30, 1419.

[29] C. Colliex, J. L. Maurice, D. Ugarte, Ultramicroscopy 1989, 29, 31. 


\section{DISCLAIMER}

This document was prepared as an account of work sponsored by the United States Government. While this document is believed to contain correct information, neither the United States Government nor any agency thereof, nor The Regents of the University of California, nor any of their employees, makes any warranty, express or implied, or assumes any legal responsibility for the accuracy, completeness, or usefulness of any information, apparatus, product, or process disclosed, or represents that its use would not infringe privately owned rights. Reference herein to any specific commercial product, process, or service by its trade name, trademark, manufacturer, or otherwise, does not necessarily constitute or imply its endorsement, recommendation, or favoring by the United States Government or any agency thereof, or The Regents of the University of California. The views and opinions of authors expressed herein do not necessarily state or reflect those of the United States Government or any agency thereof or The Regents of the University of California. Ernest Orlando Lawrence Berkeley National Laboratory is an equal opportunity employer. 